\title{
On the Basis of the Program Design Teaching and Research of Cultivation of Computational Thinking Ability
}

\author{
XIA aiyue \\ The Armed Police Academy \\ Managing Department \\ Lang fang Province, China \\ 52859624@qq.com
}

\begin{abstract}
After analyzing the current situation of Computer Programming Course, it presented that computational thinking should be trained in program teaching. And then further proposed the use of the Case Teaching in program teaching courses, as well as task-driven, micro-lesson, MOOCs and other advanced teaching philosophy to cultivate students' computational thinking ability and it improved the students' ability of computational thinking. It will be more helpful in developing all abilities for student in the future.
\end{abstract}

Keywords-computational thinking; computer programming; visual basic; graded teaching; MOOCs

\section{INTRODUCTION}

With the rapid development of computer science, computer has been widely applied to various areas of society, the various sectors of society to the level of computer applications become increasingly demanding. It is the basic quality that with computer processing capability transaction for every member of society. Students must have the ability to use and apply of computer technology, especially for capabilities of comprehensive data processing. The computer is no longer just a tool for students and to learn computer courses have not only learned to use a computer, but by learning the computer one or several courses and gradually mastered a way of thinking ---computational thinking, this way of thinking for future students will be engaged in any work of a lifetime.

July 2010, "C9 League (C9) Computer Basic Course Seminar" held in Xi'an Jiaotong University, the C9 League (C9) clearly put forward the "training of computational thinking ability" as the core task of teaching basic computer as in [1]. From computing power to develop computational thinking, it is a new challenge for computer teaching of the country's colleges and universities. However, how to cultivate students' computational thinking ability in computer programming courses is an issue of concern by the majority of computer education.

In this paper, how a computer program curriculum students' computational thinking ability is illustrated by the case of a computer program teaching Visual Basic to describe.

\section{The Present Situation of Computer Programming COURSE}

\section{A. The Students' Computer Level Is Different}

Now, a lot of high school even elementary school opened information technology courses and many college students think that they have learned similar information courses and they have a good basic computer knowledge and ability to operate. However, the actual situation is not the case. Due to the regional differences, college entrance examination because of factors, the computer level of the students is not the same. Most of the students had no systematic studied in computer related courses, ability of operating computer still remain playing games and chatting.

It is even more obvious difference that students had learned basic computer courses. While the effect of computer program teaching is not ideal. And many programming teachers have been plagued by this situation.

\section{B. Reduction of Class Hours And Teaching Content More}

Experts in many colleges and universities are being the idea of "narrow tool theory" about the computer, they think that computer is the modern society as a tool, so various colleges and universities are in greatly compressed computer teaching classes, and the content of the computer which requires is increasing. Because there are so many basic computer programming course knowledge points, teachers want to teach students more knowledge. While teaching content is very difficult to be absorbed by the students and then they generally reflect only rote textbook knowledge, problem-solving methods, important examples or exercises. They will soon forget knowledge after exam. The education which they receive is the Exam-oriented education.

\section{The Teaching Form Is Single And the Training of the Computational Thinking Ability Is Ignored}

Now the basic computer application teaching is usually a teacher on the platform, the students passively listening to, participation in the whole process of teaching high school students are not high; Basic teaching mode is to systematically 
teach first, and then arrange the corresponding practice, practice is usually imitate type. Teacher let the students to imitate the similar subject of the classroom teaching. Such teaching model for students' practical ability and problem solving ability training results are not very ideal.

The teaching content tends to focus on knowledge, ignore the cultivation and training of computational thinking. Some teachers like to teach knowledge, but not theoretical knowledge taught systematically and think only listening can master more relevant knowledge. They don't realize that the calculation of students thinking ability is a long and gradual process. It is not limited in explaining the teacher knowledge and examples.

Such teaching methods will lead to students lack the ability to map the mathematical model for the computer model and the computational thinking is weak that is flexible algorithm application ability is insufficient. The fundamental way to solve the above problem is introducing computational thinking to "programming" course teaching.

\section{DEFINITION OF COMPUTATIONAL THINKING}

Chinese ancient Counting Rod, Abacus and modern Western countries, has calculated adder prototype thinking, but for a long time, the definition of "computational thinking" is not a complete and clear. Until March 2006, Carnegie Mellon University • Department of Computer Science Professor Zhou Yizhen for the first time in the prestigious journal Communications of the ACM on the proposed "computational thinking" (Computational Thinking): computational thinking is the use of the fundamental concepts of computer science will be problem solving, understanding of human behavior as well as system design thinking activities as in [2], which includes a series of covers computer science thinking activities. By Professor Zhou's point of view that computational thinking is based on theoretical calculations and it beyond the computer itself. Calculations are not necessarily done on the computer and to be completed in the human brain, so the most essential computational thinking is abstract (Abstraction) and automation (Automation) as in [3]. We can also interpret it this way: the problem is the introduction of computational thinking, inductive, solving; the idea of the whole process can also be understood as an unknown number of known problems become progressively generalize the problem solving process last as in [4].

\section{DeVeloping Students' COMPUTATIONAL Thinking ABILITY IN THE TEACHING OF COMPUTER PROGRAMMING}

It is including the thinking process, design and calculation process in a series of the process of using computer to solve the problem of. For a given problem, it must analyze the question firstly which is the thinking process; And then it describes in the form of algorithm using the specification which is namely the design process; At last, through computer programming language combined with the computer algorithm make the issue is resolved which is the calculation process. Obviously, the computational thinking has been throughout the course of computer to solve the problem, forming their thinking and to write programs, the target is around the computability of mind or operability, namely the computational thinking as in [5].
In program design course, all kinds of problem solving methods and algorithms, such as selection and bubble sort, recursive method, binary search, the Fibonacci sequence and Hanoi problem is to calculate thinking methods as in [6]. A course is not entirely contains all contents of computational thinking, it needs a series of computer courses together complete calculation of the cultivation of thinking ability. Therefore, it must pay attention to the development of thinking ability for computing in program design course. It has very important significance and the improvement of students' practical ability for students after learning professional courses.

Computational thinking is different from the traditional mathematical thinking. It emphasizes the process of problem solving. In the interpretation of the theory of knowledge teachers should pay attention to choose the appropriate teaching way and method which can better describe the concept of complex simplification and let students understand the origin of the concept, for such as data storage, data types, functions. It is to let students understand other important concept, such as arrays, custom types, data structure, etc. In addition, teachers also pay more attention to cultivating students' ability to solve scientific problems and convert this ability to the practice of the actual programming ability.

\section{A. Graded Teaching}

Suit ranking is the best way of teaching. The best way to implement individualized teaching is graded. Taking into account the differences in student computer-based cognitive status of large differences in level and learning needs to fundamentally change the "one size fits all" teaching methods, students should begin to mobilize the enthusiasm of starting, follow the "individualized education plans" principle. we can try to divide the students into Exemption classes, fast classes and regular classes three level, hierarchical teaching in the form of stratified teaching. we can carry out the grading examination, Who can achieve the standard exemption of the course can be qualified to obtain appropriate time to make this part of the students to study independently through the Internet and other channels. Through graded teaching practice, we found that the students the effect of exemption is not good. Although some students have some basic programming Fundamentals, but most programming knowledge is scanty. So the student is usually divided into two design courses level that is fast classes and regular classes. For entering the fast class courses for students, classroom teaching hours shortened to provide more hours of online learning and hands-on practice, these students mainly through independent learning and networked learning way to complete this course of study in a short time. For students who entered the fast class courses, we can shorten classroom teaching hours to provide more hours of online learning and practicing. They mainly complete this course of study through independent learning and networked learning way to in a short time. For the students of the normal classes, we can tutor and guide to increase learning methods; the introduction of individualized teaching must learn and choose to learn the form of a combination. We can depend on the class characteristics and circumstances of individual students let student choose to study in learning content in this way to ensure that the learning is the needs of their. Thus we 
can enhance the consciousness of students to solve the contradiction student diversity.

\section{B. Using Case Law And Task-Driven Teaching Methods For Teaching}

Select interesting typical examples in programming to guide students to read and think about the program, so that they experience the problem-solving methods and ideas. After discussing the case, we should highlight the relevant knowledge arouse students' interest in learning. This method largely solves boring programming language syntax rules and avoids losing interest in learning problems for students. Project-driven in program teaching will help students calculate thinking ability and self-learning ability, students' ability is by allowing students hands-on "doing" to culture; Students' ability are trained while the Cases and tasks are completed. Students can acquire knowledge and improve students' ability to learn by analogy through easy and difficult cases to guide.

\section{Using the Advanced Teaching Concepts Such as Micro Class And MOOCs for Teaching}

We can combine classroom instruction, computer experiments, micro-classes, MOOCs-classes, teaching materials and other resources and create three-dimensional learning environment to enable students to become the subject of learning activities. From teacher-centered really into student-centered, which is actually a combination of traditional and modern and its effect is much better than traditional teaching. And such active learning can conducive to the formation and training of computational thinking. It is a well method which can develop students' computational thinking.

We can introduce MOOCs works which are more recognized by the interactive to modern classroom teaching, but we should be properly controlled the number of MOOCs lessons or micro-lessons and they should not overwhelming. The teaching forms are not just the form that we admire lessons or micro lesson works mechanically to move to the classroom and make good use of these advanced teaching methods. Thus we can better calculate the thinking ability of students etc.

Now, it expounds how to cultivate students' Computational Thinking Ability in computer programming teaching with Basic Visual program design as an example.

- Display of works

Before teaching Visual Basic programming, we can display a few program which written by Visual Basic (preferably developed by our students) and tell students that through a semester they can have the ability to develop applications. Students will be appreciated by these systems and will have a strong sense of curiosity and desire for knowledge. Thus we can stimulate student to interest in study and contribute to the development of teaching. After showing programming, students will have intuitive perceptions to programming and then expanding the teaching will be much easier.

\section{- $\quad$ Analysis of works}

Select a moderate difficult works as an analysis object, the application will be able to cover most of the knowledge points, including various types of knowledge, such as variables and variable types, objects, functions, three basic structures, arrays, reading and writing files, the definition and use of variables including numeric, Boolean, character, and other variables. After showing, we should arouse students' interest and curiosity and each class may began with a few questions.

Through the work, to make students see people's "thinking” the computer is able to achieve. Such as data sort part of the work, through the choice of sorting algorithms, the algorithm of computing thinking expression, the implementation algorithm of the choice of language to complete the data sorting, causes the student to experience the reliability of "thinking"; Through everyday teaching subtly rooted in student's daily thinking, make its independent build computational thinking in practice, promote computing ability and innovation ability.

Teaching content, the exchange of two variables, statements can be combined with the real life "a bottle of water and a bottle of orange juice exchange" the concrete methods of teaching. Everyone knows to exchange "a bottle of water and a bottle of orange juice", we can use an empty bottle, specific exchange process. We also know that this image intuitive teaching method, students need to use the content of the exchange of two variables, three statements deep memory. With examples of application of knowledge, introduced from the problems, driven by knowledge mastered the rules of grammar, to make the students deepen the understanding of computational thinking.

\section{- $\quad$ Practice and Exercises}

In order to stimulate students' interest, we can encourage students to participate in scientific and technological innovation activities. Give students some of the program design contest held by the school or the national information and data, students according to their own choice and the actual development ability grouping independently. The difficulty level of the application can be divided into low, medium and high thus three levels. Grouping principles can be free combination. According to the demand of the development and application to give students some demonstration cases in time and give the corresponding guidance. Such, students can according to their own actual situation from easy to difficult to do advanced practice and improve.

\section{- $\quad$ Feedback and Evaluation}

Teachers should test and evaluate students' works. And while students meet a difficult teachers should give timely help and guidance. While their methods used should not be corrected in a timely manner, teachers 
should give some help. While class time is limited, teachers can use the micro class, MOOCs class, micro letters and QQ variety of ways for students to guide and help. To encourage students to innovation, students ground thinking, and gradually develop their computational thinking ability by and by.

\section{- $\quad$ Content Development}

After examination, students can take part in the National Programming Contest which will be held every year and teachers should try to encourage students to make good works. To provide students with timely and relevant information on a number of instructional videos, so students can use their spare time to further enhance the ability of computational thinking and gradually improve the teaching and practice in the process by and by.

\section{SUMMARY}

With the rapid development of computer science, the future is the era of unlimited development of Electronic Science and Technology, and only has the ability of computational thinking, mastered the use of the calculation method of thinking and better equipped to analyze problems and problem-solving skills.
The cultivation of computational thinking ability has a pivotal position in the computer program design course, how to strengthen the cultivation of students' thinking ability in teaching computing, a computer program is the Teaching of core tasks. Teachers in ascending actual computer design teaching should do more practice, more summary and try to find better teaching methods and ways to promote students' computational thinking ability.

\section{REFERENCES}

[1] Nine school league(C9). Computer basic course seminar nine School Unio(C9). A joint statement on the development strategy of computer based Teaching [J]. Chinese University Teaching[J],2010(9):4-9.

[2] Wing J M. Computational thinking [J]. Communications of the ACM, 2006, 49(3): 33-35.

[3] Zhou Yizhen. computational thinking [J]. China Computer Society Newsletter, 2007, 3(11): 83-85.

[4] Liu Yuyan,Ding Haiyan,He Hongling.C language program design [M].Beijing: Science Press,2015

[5] Liu Yuyan,Ding Haiyan,He Hongling.C language program design [M].Beijing: Science Press,2015

[6] [6]Huang Jing,Gao Yanying,Yang YushuResearch on the teaching mode of programming course based on Computational Thinking [J].Computer Education,2013(5):32-36 